\title{
Thai hotel undergraduate interns' awareness and attitudes towards English as a lingua franca
}

\author{
Waraporn Suebwongsuwan and Singhanat Nomnian* \\ Research Institute for Languages and Cultures of Asia, Mahidol University, \\ 999 Phutthamonthon Sai 4 Rd., Salaya, Phutthamonthon District, Nakhon Pathom, Thailand 73170
}

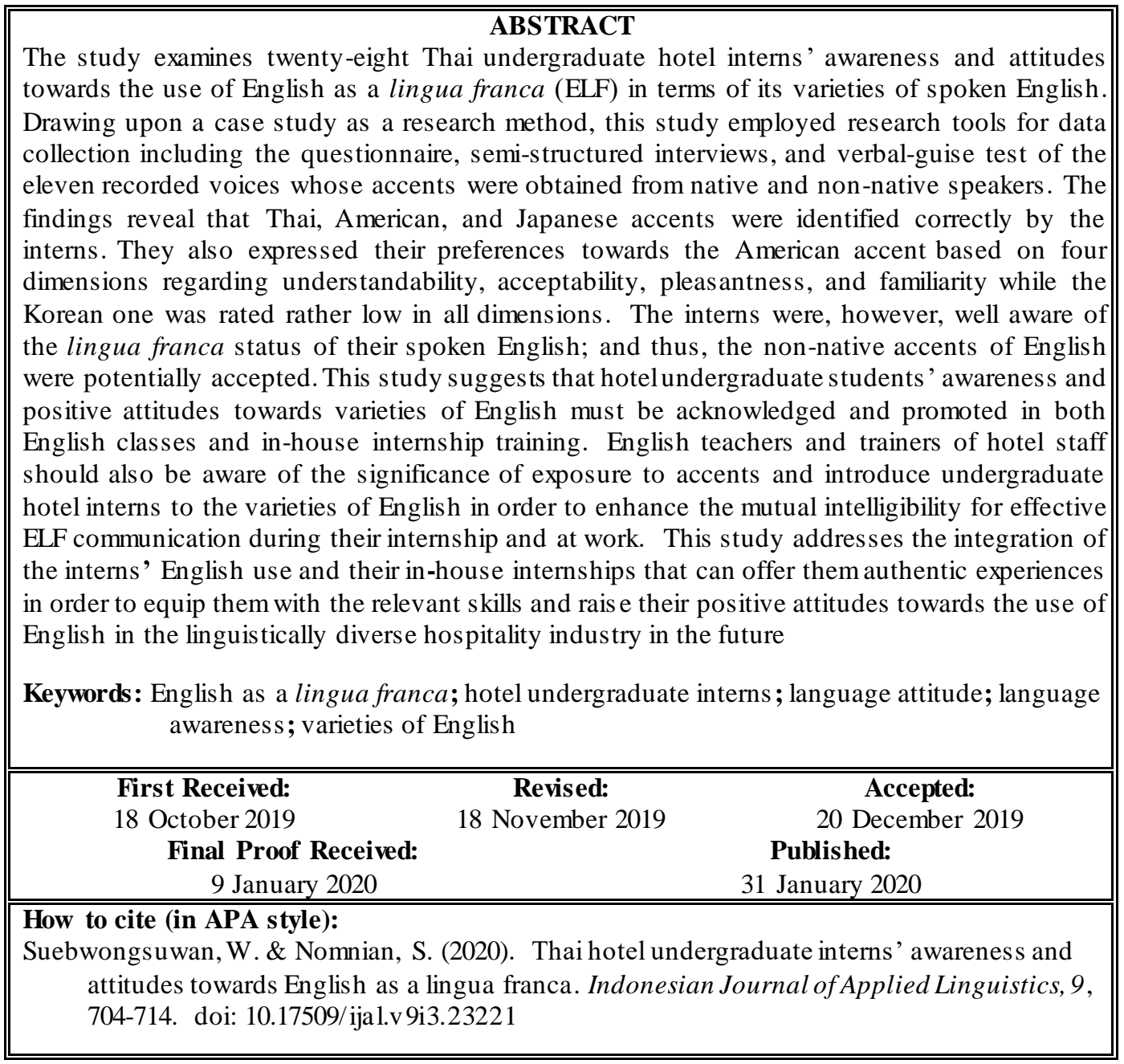

\section{INTRODUCTION}

As English is an effective means for international communication at work and education, it has become one of the important factors that drive socio-economic development; and thus, there are growing demands for English speakers in the job market. Adopted as a medium of communication in various education and business contexts, English is recognized as a lingua franca (ELF hereafter), which is used by speakers who do not share the first language (Nomnian, 2014; Phumpho \& Nomnian,
2019; Suwannasri \& Nomnian, 2017). It seems, however, to be a flexible method of communication; and currently, there is a call for more effective skills in communication in order to gain a competitive advantage. Moreover, English has been selected as an official language of communication among countries in the ASEAN community (ASEAN Secretariat, 2009). Hotel trainees or staff are normally expected to speak English fluently and ready to cope with all challenges in the tourism and hospitality industry (Jhaiyanuntana \& Nomnian, 
2020). Tourism requires skilled workers to be in compliance with ASEAN policies on the free flow of skilled workers (ASEAN Secretariat, 2009; Crocco \& Bunwirat, 2014).

Tourism has contributed significantly to the Thai economy that can be seen from the number of international tourist arrivals to Thailand annually. Over the past few decades, tourism has contributed at least $6.5 \%$ to Thailand's GDP, and current predictions put that number at between $9 \%$ and 10 $\%$ (National Statistical Office of Thailand, 2017, p.1). In addition, the ten most popular nationalities to visit Thailand during 2017 were: Malaysian, Japanese, Laotian, Korean, American, Indian, Russian, Singaporean, and British nationals, respectively. However, by late 2018, Vietnamese and Hong Kong nationals had taken the top two places ranking knocking champions, namely Singapore and the United Kingdom out of the top ten.

Based on these data, an increase in tourismrelated workers is required to meet the demand in Thailand. Furthermore, the severe lack of skilled workers in the industry has become a major concern for the government. According to the National Economic and Social Development Plan (2017, p. 65-68), "the main focus of the government is to develop the workforce through essential skills preparation and required for competencies that would meet the national social and economic development and job market needs."
Several research studies (Rungruangsuparat, 2010; Suwannasri \& Nomnian 2017; Zourgui, 2012) have been conducted in order to explore the link between hotel workers' attitudes and their behaviours toward guests, the results of which suggest a positive correlation. When staff have a positive attitude towards customer service, they tend to show greater responsibility and friendlier manners in meeting their guests' expectations and requirements (Jhaiyanuntana \& Nomnian, 2020). Few studies, however, have been conducted with Thai undergraduate interns, who will play a significant role in tourism and the hospitality industry in Thailand (Dhevabanchachai \& Wattanacharoensil, 2017). The aim of this study is, therefore, to explore the attitudes and awareness of hotel undergraduate interns with regard to varieties of spoken English to determine their effect on their service performance and communication.

\section{English as a Lingua Franca}

English as a lingua franca (ELF) has been defined and conceptualized in a number of ways. A functional definition was devised by Seidlhofer (2011, p. 7) as "any English used among different speakers; those who used English as a medium to communicate as a choice or just the option." ELF, according to Jenkins (2006), is to do with English communication between different linguacultural users. It was later clarified by Jenkins (2007) as being not restricted to members of the first of the three circles once proposed by Kachru (1985).

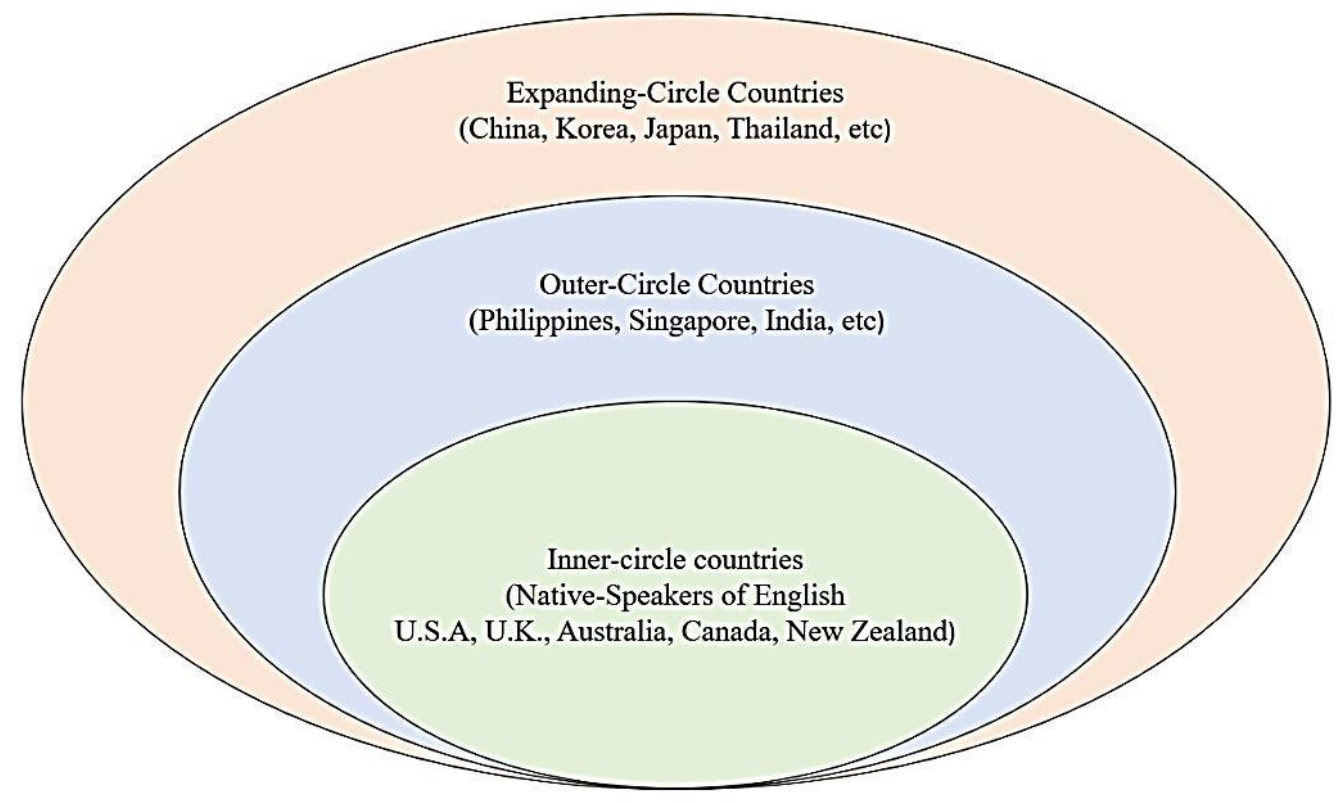

Figure1. Kachru's Three Circles of English (1985)

Kachru (1985) divided English speakers into three circles: the inner, outer, and expanding. The inner circle refers to the English used by native speakers, including countries like U.K., Ireland, Australia, New Zealand, Canada, and USA. The outer circle are those countries that use English as the official language such as Singapore, the Philippines, and India. Lastly, in the expanding circle are countries that use English as a foreign language, such as Japan, Korea, and China. English 
is a global and international language due to its role in communication worldwide among native and non-native speakers.

Moreover, according to Jenkins (2007), Kirkpatrick (2010), and Suwannasri and Nomnian, (2017), the use of ELF has gained considerable interest from researchers in numerous fields in a large number of language aspects. At present, English is the international lingua franca, with an estimated 80 per cent of users being non-native. However, previous studies on World Englishes (WE), ELF, or English as an International Language (EIL), most non-native English speakers are only slowly changing their conception of English (Jenkins, 2007; Galloway \& Rose, 2015), and most viewed English as primarily the British and American language. Attitudes surveys on the norms of native speakers invariably reveal that the majority of language learners and teachers of English remain of the view that English belongs to countries of the inner-circle (Jenkins, 2007; Matsuda, 2003; Timmis, 2002); and as a result, non-native English speakers struggle to advance their relationship with and ownership of English.

In Thai higher education, ELF influences the attitudes of Thai students in terms of the varieties of spoken English, which has implications for the development of effective English language teaching (Nomnian, 2014a; Phothongsunan, 2017). In addition, Thon and Nicoletti (2018) highlight how English functions within a Thai ELF university context where students have opportunities to use English; it reduces their anxiety about using English. Some Thai students' communicative anxiety results from communication apprehension, lack of self-confidence, and fear of negative evaluation (Inphoo \& Nomnian, 2019; Nomnian, 2018; Nomnian \& Arphattananon, 2018). In the hos pitality industry, the global spread of English has significantly influenced and challenged Thai tourism professionals, and vice versa, for the reason that it is so common in international workplace settings today (Phumpho \& Nomnian, 2019; Zahedpisheh et al., 2017).

In the development of sustainable international tourism, English is a constraint and the main barrier between Thai services and international tourists (Dolezal, 2011). Thai tourism entrepreneurs needed to improve their English communicative fluency rather than accuracy because many of their foreign customers and clients are also from outer-circle countries like Myanmar and India; and expandingcircle countries like Japan and Korea. Thus they need to improve their listening and speaking skills with various "non-standard" forms of English (Nomnian, 2014b; c). Raising Thai tourism workers' awareness of non-native varieties of spoken English accents can achieve mutual intelligibility and improve their self-confidence in intercultural communication (Inkaew, 2018).

\section{METHOD}

\section{Research participants and setting}

The case study was employed in this study because, according to Ruiz-Ballesteros (2017), it addresses factors regarding situated practices in certain tourism settings. An in-house hotel training centre located on the university campus was selected as a research setting for the study. The hotel is situated on the top floor of the international college building at a research-based university in Nakhon Pathom province. This hotel is not solely used for accommodation, but also serves as an in-house training centre where undergraduate students in the hospitality industry are trained, shaped, and developed into hotel professionals.

Both quantitative and qualitative approaches were used to examine the awareness and attitudes of Thai hotel undergraduate interns towards varieties of spoken English. There were twenty-eight participants in this study. Thirteen of them were third-year students, and the rest were fourth-year students. They were studying for a Bachelor of Business Administration (BBA) degree in Tourism and Hospitality Management for which the threemonth-long in-house internship at this hotel was a requirement.

The participants were selected as the sample group using purposive sampling as they were studying in an international program and would certainly have had experiences in learning and interacting with foreigners, both native speakers and non-native English speakers alike. In addition, they were being trained at the in-house hotel training centre renowned for its quality service. As a result, they would likely gain additional experience using English as a medium for communication and interaction with guests of different languages and cultures. Their language skills and practical skills would be required in real-life situations in which they would serve guests from all over the world. While other universities offered an equivalent program in Thai language only, the Tourism and Hospitality Management program at this university employed an international curriculum taught in English by foreign and Thai teachers. The participants' names were kept anonymous. The research ethics of this study were approved by the Institute of Population and Social Research, Mahidol University (IPSR-IRB-2018/08-223).

\section{Instruments}

The data collection tools, including questionnaire, verbal-guise test, and semi-structured interview employed in this study were as follows.

\section{The questionnaire}

To investigate the participants' awareness and attitudes towards English, a questionnaire was adapted from other attitude questionnaires of Jenkins (2007) and Suwannasri (2016), which was 
divided into two main parts: awareness of varieties of spoken English and attitudes towards the use of ELF.

\section{The verbal-guise test}

The questionnaire included a verbal-guise test, which is an efficient technique frequently used in studies on attitudes towards accents and recognition (Garrett et al., 2003). The stimuli used in the research verbal-guise test were voice recordings from ten varieties of spoken English and one Thai speaker. These recorded voices obtained from various forms such as interviews, news reports, and talk shows, were acquired from YouTube. The last audio voice recording belonged to the Thai speaker. The voice recordings from eleven speakers were selected according to the statistical information of international tourists arriving in Thailand in 2018, namely, China, Malaysia, Korea, Japan, Lao PDR, India, United State, Vietnam, Hong Kong, and Russia, respectively (National Statistical Office of Thailand, 2018).

The voice recordings were played twice during the verbal-guise test. The participants were then asked to rate the eleven accents according to a bipolar semantic differential scale designed to examine participants' awareness and attitudes. The bi-polar semantic differential scale is normally applied in verbal-guise tests and requires the listeners to rate the voice heard and give their opinions on different aspects (Garrett et al., 2003).

\section{Semi-structured interviews}

The semi-structured interviews were conducted with ten volunteer hotel student interns following the completion of the questionnaires. The interns provided personal information in the final section of the questionnaire for their consent to be interviewed. Seven students agreed to be interviewed face-toface. The rest, however, were unable to be interviewed face-to-face due to their personal issues and time constraints and were asked to do an email interview instead. According to Bowden and Galindo-Gonzalez (2015), since people increasingly use the Internet for communication, researchers may need to start to do interviews via email. The main advantage of using email for interviews is that it can save travel time where distance is an issue. Moreover, participants in email interviews can provide answers at their own convenience with more time to reflect on the question in order to give more detailed answers (Bowker \& Tuffin, 2004; Cooper, 2009; Opdenakker, 2006). follows.

The examples of the interview questions are as

1. Do you think English is important in your daily life? How?

2. Do you use English in your everyday life? If yes, on what occasions?
3. Have you made special efforts to improve your English? How?

4. During the doing in-house internship at a hotel training centre, have you had experiences of communication with guests from different countries?

5. Have you had any experience of English used in different counties? If yes, how?

6. What do you think about varieties of spoken English in terms of different accents?

7. What do you think about native English accents and non-native English accents?

8. Do you think it is important to study the different accents of English around the world? Why?

9. After listening to the eleven voice recordings of speakers from different countries, what were your attitudes towards each speaker

The length of each interview was approximately 25-30 minutes. The interviews were conducted in either English or Thai, depending on the preference of the participants. A digital taperecorder was used to record each interview, which was then transcribed verbatim after the interview session and sent to each participant to verify the accuracy.

\section{Data analysis Quantitative data analysis}

The questionnaires provided quantitative data that was checked before entering into a Statistical Package for Social Science (SPSS) program to calculate the results presented in tables. The study provides the following statistical information regarding frequency, percentage count, mean, and standard deviation. The frequency and percentage were calculated to determine the levels of the correct identification of each accent rated by the interns and their attitudes towards ELF. The average value of the data set (mean or $\bar{x}$ ) and standard deviation (S.D.) were also determined by using descriptive statistics to indicate the participants' attitudes based on the questionnaires and the verbal-guise test. Jenkins's (2007) rate scale was applied for the data interpretation according to four dimensions: understandability, acceptability, pleasantness, and familiarity.

According to Jenkins (2007) and Suwannasri (2016), the interpretation of attitudes and data voice stimuli using the 6-point scale are presented below with the mean score ranges for each level.

Data interpretation of the participants' attitudes towards the questionnaire statements using the 5point Likert-scale, as can be seen in Table 2, is based on the following mean scores underpinned by Jenkins (2007) and Suwannasri (2016). 
Table 1. The 6-point scale interpretation

\begin{tabular}{cc}
\hline Score range & Interpretation \\
\hline $5.20-6.00$ & Very high \\
$4.36-5.19$ & High \\
$3.52-4.35$ & Slightly high \\
$2.68-3.51$ & Slightly low \\
$1.84-2.67$ & Low \\
$1.00-1.83$ & Very low \\
\hline
\end{tabular}

Table 2. The 5-point scale interpretation

\begin{tabular}{ccc}
\hline Score range & Mean rating & Interpretation \\
\hline $4.21-5.00$ & strongly agree & very positive \\
$3.41-4.20$ & agree & Positive \\
$2.61-3.40$ & unsure & Moderate \\
$1.81-2.60$ & disagree & Negative \\
$1.00-1.80$ & strongly disagree & Verynegative \\
\hline
\end{tabular}

\section{Qualitative data analysis}

According to Schmidt (2004), the analytical techniques selected for semi-structured interviews depend on the objectives, questions and methodology, as well as the available length of time, research tools and resources. To analyze the interview transcripts, Taylor-Powell and Renner's content analysis (2003) was used according to the five steps as follows: data recognition, focused analysis, data categorization, identification of patterns and connections between and within categories, and data interpretation.

\section{FINDINGS}

This section reports the main findings regarding the students' awareness and attitudes towards the varieties of spoken English on language learning and pronunciation; each of which will be discussed in turn.

\section{Awareness of the varieties of spoken English}

Firstly, the eleven varieties of English accent were measured either by correct or incorrect identification of the accent. The accent identification was made regardless of whether the participants were aware of each English accent used as the research stimuli. Table 3 shows the results of the correct identification.

Table 3. Correct identification of the origin counties of the speakers

\begin{tabular}{lcc}
\hline \multirow{2}{*}{ Origin countries of the speakers } & \multicolumn{2}{c}{ Correct identification } \\
\cline { 2 - 3 } & Frequency & Percentage \\
\hline America & 28 & 100 \\
Thailand & 28 & 100 \\
Japan & 28 & 100 \\
China & 24 & 85.7 \\
Vietnam & 22 & 78.6 \\
India & 18 & 64.3 \\
Korea & 18 & 64.3 \\
Russia & 15 & 53.6 \\
Malay sia & 11 & 39.3 \\
Lao PDR & 4 & 14.3 \\
Hong Kong & 1 & 3.6 \\
\hline
\end{tabular}

According to Table 3, the highest percentage of the correct identification of the eleven speakers' countries of origin was $100 \%$ while the least was $3.6 \%$. There were three countries that all participants could correctly identify the accents, namely the United States of America, Thailand, and Japan. These were followed by China with 24 participants correctly identified $(85.7 \%)$, and Vietnam, recognized by 22 participants $(78.6 \%)$. Two countries were correctly identified by 18 participants $(64.3 \%)$, which were India and Korea, and $15(53.6 \%)$ participants identified Russia correctly. Less than half of the participants recognized the three remaining countries. The percentage of the correct identification of the last two was below $20 \%$. Malaysia, Lao PDR, and Hong Kong were accurately selected by $39.3 \%, 14.3 \%$ and $3.6 \%$ of participants, respectively, and only one participant chose Hong Kong correctly.

\section{Attitudes towards varieties of spoken English}

In the verbal-guise test, the results of accents based on the four dimensions regarding understandability, acceptability, pleasantness, and familiarity, are presented in Table 4.

The results reveal that none of the accents was rated as "very low." As can be seen in Table 4, the American speaker was rated the highest for all dimensions, especially as regards familiarity $(\overline{\mathrm{x}}=$ 5.96) and rated very high in all aspects. The next highest-ranked accent was the Hong Kong accent, which obtained a high evaluation for three dimensions and very high for understandability $(\overline{\mathrm{x}}=$ 5.29). The Laotian accent was ranked in third place, rating high for all aspects except pleasantness, which scored slightly high. The Thai accent was ranked fourth with three dimensions rated at a high level, but pleasantness was slightly low $(\overline{\mathrm{x}}=3.46)$. Apart from the four accents mentioned above, no other accent was rated high $(\overline{\mathrm{x}}=4.36$ or above $)$ for any dimension; most were rated slightly high or slightly low. The Malaysian, Russian, and Chinese accents were rated as slightly high for all except 
pleasantness, which was rated slightly low. The Indian accent scored slightly high with regard to acceptability $(\overline{\mathrm{x}}=3.57)$ and familiarity $(\overline{\mathrm{x}}=3.71)$, but slightly low for understandability $(\overline{\mathrm{x}}=3.36)$ and pleasantness $(\overline{\mathrm{x}}=3.21)$. As for the Japanese accent, it obtained a slightly low rating in all dimensions with a mean score of 3.17. Similarly, the Vietnamese accent rated slightly low for all dimensions apart from pleasantness at 2.54. The lowest ranking accent was Korean, which was rated low for every dimension, with a mean score of 2.24.

Table 4. Overall means and standard deviation in 4 dimensions

\begin{tabular}{lcccccccc}
\hline \multirow{2}{*}{ Countries } & \multicolumn{2}{c}{ Understandability } & \multicolumn{2}{c}{ Acceptability } & \multicolumn{2}{c}{ Pleasantness } & \multicolumn{2}{c}{ Familiarity } \\
\cline { 2 - 9 } & $\overline{\mathbf{x}}$ & S.D. & $\overline{\mathbf{x}}$ & $\mathbf{S . D .}$ & $\overline{\mathbf{x}}$ & S.D. & $\overline{\mathbf{x}}$ & S.D. \\
\hline America & 5.89 & 0.32 & 5.86 & 0.45 & 5.43 & 1.00 & 5.96 & 0.19 \\
Hong Kong & 5.29 & 0.94 & 5.11 & 0.99 & 5.00 & 1.02 & 4.71 & 1.12 \\
Lao PDR & 4.89 & 0.99 & 4.79 & 1.00 & 4.18 & 0.98 & 4.64 & 0.87 \\
Thailand & 4.96 & 1.23 & 4.07 & 1.42 & 3.46 & 1.40 & 5.18 & 1.34 \\
Malay sia & 4.18 & 1.02 & 4.00 & 0.90 & 3.50 & 1.00 & 3.89 & 0.99 \\
Russia & 4.04 & 1.26 & 4.18 & 1.28 & 3.04 & 1.32 & 3.71 & 1.27 \\
China & 3.79 & 1.07 & 3.64 & 1.03 & 3.36 & 1.13 & 4.04 & 1.07 \\
India & 3.36 & 1.25 & 3.57 & 1.29 & 3.21 & 1.17 & 3.71 & 1.33 \\
Japan & 3.00 & 1.59 & 3.18 & 1.39 & 2.96 & 1.23 & 3.57 & 1.40 \\
Vietnam & 3.00 & 1.52 & 3.36 & 1.19 & 2.54 & 1.07 & 2.96 & 1.04 \\
Korea & 2.36 & 1.25 & 2.32 & 1.16 & 2.00 & 1.02 & 2.29 & 1.15 \\
\hline
\end{tabular}

Attitudes towards learning English

Attitudes towards learning English were obtained from the questionnaire and semi-structured interviews. The participants were asked to rate the accuracy of statements in the questionnaire based on the 5-point Likert scale. Table 5 shows the participants' attitudes towards learning English.

Table 5. Attitudes towards learning English

\begin{tabular}{lccc}
\hline Statements & $\overline{\mathbf{x}}$ & S.D. & Interpretation \\
\hline 1. The tourism and hospitality industry considers it necessary to learn English. & 4.82 & 0.39 & Very positive \\
2. English is studied with an aim to communicate with people from around the world, & 4.36 & 0.83 & Very positive \\
$\quad$ not only native speakers of English. & & & \\
3. I prefer not to study English with non-native speakers of English. & 2.64 & 1.34 & Moderate \\
\hline
\end{tabular}

From the results shown in Table 5, Thai hotel undergraduate interns considered that learning English was necessary for the tourism and hospitality fields $(\bar{x}=4.82)$. Moreover, the participants indicated that they studied English in order to communicate with people worldwide, not only restricted to native speakers of English $(\overline{\mathrm{x}}=$ 4.36). Their preference to study English with nonnative speakers of English was, however, only moderate $(\bar{x}=2.64)$. Subsequent to the questionnaires, in the semi-structured interviews, ten participants said they aimed to communicate in English with foreigners. The following extracts reveal their opinions and purposes for studying English.

\section{Extract 1}

Moreover, it may influence future work, because working in hotels, of course, you must meet foreign guests. Most of them are either native speakers or non-native speakers, so we definitely have to encounter English in a variety of accents. (Student 10)

Looking forward to working in the hospitality industry, the student was prepared for exposure to the varieties of spoken English used by international guests worldwide.

Extract 2
The advantage is that I have learned English in a variety of accents, not just native accents. For example, if I meet someone Japanese, I can detect that they are from Japan from their accent. (Student 2)

Similarly, the intern student valued the learning of a variety of spoken English based on other non-native accents, including Japanese, which represented realistic communicative functions at the hotel. Exposure to these varieties is related to the students' attitudes, which will be presented next.

\section{Attitudes towards English pronunciation}

The questionnaire was designed to examine the participants' attitudes towards English accents and pronunciation. The results of each question were displayed in Table 6.

Table 6 shows that the participants strongly preferred to speak English like native speakers of English $(\bar{x}=4.54)$. However, they indicated that no matter whether speakers had accents, it was not problematic for them as long as they could understand each other $(\bar{x}=3.57)$. Moreover, most of the participants strongly agreed that they wanted to have more knowledge of the English accents of people from different countries to understand them better $(\bar{x}=4.11)$. Statements 6 and 7 shared similar questions, but statement 7 was written in its negative 
form recorded a mean score of 1.82, which indicates a negative attitude towards the statement. From the results then, most of the participants had a positive attitude towards speaking English with non-native speakers. Most of them, however, were unsure about statement 8 , which reflects a moderate attitude towards the statement. This means that about half of all participants considered that non-native English accents could prove to be a challenge in English communication $(\overline{\mathrm{x}}=2.82)$.

Table 6. Attitudes towards English pronunciation

\begin{tabular}{lccc}
\hline Statements & $\overline{\mathbf{x}}$ & $\mathbf{S . D .}$ & Interpretation \\
\hline 4. I need to be able to speak English like a native speaker (e.g., British, Irish, American, & 4.54 & 0.58 & Very positive \\
Australian, Canadian, or New Zealander). & & & \\
5. I do not pay much attention to the speaker's accent as long as I can still understand & 3.57 & 1.23 & Positive \\
them. & & & \multirow{2}{*}{ Positive } \\
6. I want to expand my knowledge of the English accents of people from different & 4.11 & 0.74 & \\
$\quad$ countries to understand them better. & 1.82 & 0.77 & Negative \\
7. I prefer not to speak English with non-native speakers. & 2.82 & 1.02 & Moderate \\
8. Non-native English accents can be an obstacle to communication. & 3.25 & 1.04 & Moderate \\
9. I like my own accent in English. &
\end{tabular}

In addition, the participants were asked whether they liked their own accent in English. Again, most of them were unsure. The mean score of 3.25 reflects a moderate attitude towards their own accent in English. The semi-structured interviews revealed similar views. With regard to statement 4 that asked whether they wanted to speak English like a native English speaker, their responses from both methods reflected that the participants preferred native-like accents to nonnative-like accents in English.

\section{Extract 3}

I think it is important to learn how native English speakers speak and it is good to have on accent like them. (Student 3)

Some respondents, however, showed a more positive attitude towards non-native speakers of English and were aware of the varieties of English and attempted to understand them, as shown in the following extract.

\section{Extract 4}

It is hard to change one's own accent if we are not native speakers. So, being aware of non-native speakers' accents is much easier, because then we will pay more attention and try to understand them better. (Student 10)

Despite the fact that native-speakers' accents are normally taught and learned in Thai universities, non-native ones have been gaining their importance and recognition, especially in the services and hospitality industries. Thus, becoming prospective hotel professionals, the students really need to familiarize themselves with all varieties of accents in English through awareness-raising by teachers and hotel trainers in both English courses and internships.

\section{Attitudes towards English as a lingua franca (ELF)}

The six questions covered in this section were about ELF in international communication. The results for each statement can be seen in Table 7 .

Table 7. Attitudes towards English as a lingua franca

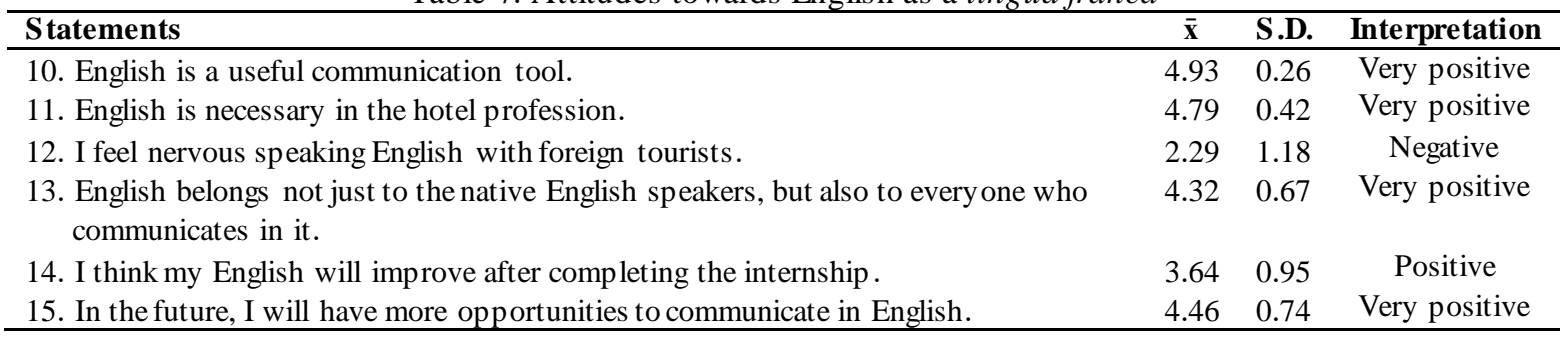

Table 7 reveals that Thai hotel undergraduate interns strongly perceived that English was a useful communication tool $(\overline{\mathrm{x}}=4.93)$, which reflected their very positive attitude. Likewise, most participants strongly agreed that English in the hotel profession was highly necessary. $(\overline{\mathrm{x}}=4.79)$. Most participants also showed that they were not scared of communicating in English with foreign tourists $(\overline{\mathrm{x}}=$ 2.29).
In addition, the participants strongly agreed that English belongs to anyone who could use it $(\overline{\mathrm{x}}=$ 4.32). The results for statement 14 reveal that most participants believed that their English skills would improve if they completed the hotel internship $(\overline{\mathrm{x}}=$ 3.64). At last, the participants showed that they would certainly have more opportunities to communicate in English with other people and use English in their daily life in the future $(\overline{\mathrm{x}}=4.46)$. 
In the semi-structured interviews, the participants were asked to discuss general topics covering the use of ELF. It turned out that most of them had experience in communicating in English with foreigners in their everyday lives. Importantly, since they were tourism and hospitality management students, all of them had an in-house internship at the university's hotel training centre. The results show that the participants used English as a medium of instruction and communication both in class and at the hotel training centre, which was illustrated as follows.

\section{Extract 5 \\ I use English every day because I have to study English in class and communicate with both Thai and foreign teachers and friends. Moreover, when I was an intern, I frequently had to use English to communicate with foreign guests. (Student 1)}

\section{Extract 6}

During my internship, I apprenticed in the front office and frequently had contact with foreign guests. Likewise, when I was stationed in the food and beverage section, I had to give advice and offer help to foreign guests. (Student 10)

The students felt strongly that the use of English in class helped with their communication at the hotel as they practised fluency rather than accuracy. The frequent use of English enabled them to provide professional services for foreign tourists.

\section{DISCUSSION AND PEDAGOGICAL IMPLICATIONS}

According to the findings, the participants tended to show more favourable attitudes towards familiar, pleasant, and recognizable accents. Moreover, the participants tended to consider accents that were easy to understand as more accepted for international communication. In this research, the results from the verbal-guise test revealed that the American accent was rated as the preferred accent in all dimensions. These findings are similar to Jenkins (2007), who found that the participants had the most positive attitudes towards American accent, followed by Hong Kong, and Laotian accents as the 2nd and 3rd highest average scores in this study. The results that the participants could recognize American accent was consistent with those of most previous studies (Jindapitak, 2010; Zourgui, 2012; Suwannasri, 2016; Prakaianurat \& Kangkun, 2018; Almegren, 2018). By adopting the verbal-guise test, this study could potentially demonstrate that there was a positive relationship between participants' experience of exposure to certain varieties of English and their recognition of the varieties.

Some accents, however, were regarded more positively in particular dimensions such as, the Thai accent, which ranked second for familiarity but was also considered slightly unpleasant in the same way as the Chinese, Malaysian, Russian, and Indian accents. These accents scored mostly slightly high for some dimensions other than familiarity and were regarded as slightly unpleasant. On the other hand, slightly negative attitudes were rated for Japanese and Vietnamese accents based on their mean scores for all dimensions. Only Korean was rated lower with a total mean score of 2.24 , which means that the participants had negative attitudes towards the Korean accent.

From the questionnaire findings, the participants were well aware of the essential use of English as a medium of instruction and communication in class, during the internship, and at future hotel contexts. While most of the participants wished to be able to speak English like a native speaker, they had positive attitudes towards ELF and varieties of non-native accents. These findings are similar to Suwannasri's (2016) results in which her participants had positive attitudes towards the use of English as a tool for communication, and they recognized the importance of English in their daily lives and future careers. The participants also reflected that English does not only belong to native speakers, but also for everyone who uses it. Moreover, they felt indifferent whether the conversation partner was a native speaker or not or what accent they had if they could create mutual intelligibility. They were unsure about the impact of non-native accents; yet, they seemed fully aware of the value and global status of English as the international lingua franca for the current study and future hotel careers.

The pedagogical implications of this study stress the need to promote positive attitudes towards varieties of spoken English and the use of ELF among Thai learners of English. This especially concerns students of tourism and hospitality, who are required to interact with international guests and use English for international communication purposes. English courses should seriously focus on students reaching a level of intelligibility rather than acquiring native speaker competency. Furthermore, it is suggested that Thai learners be encouraged to consider varieties of spoken English positively and a greater emphasis placed on English teachers and hotel trainers introducing a variety of accents into classroom activities and teaching materials via the use of ICT. This would expose English learners and hotel undergraduate interns to non-standard accents and facilitate communication and work competence in an increasingly multilingual international business environment.

Similar to Dhevabanchachai and Wattanacharoensil's (2017) research on hotel students' in-house internship, this study highlights the integration of students' English use and professional internships that can provide realistic practice of intercultural communication to equip 
them with the requisite skills for the tourism workplace of the future. How and the extent to which English language teaching and learning should incorporate non-native varieties of spoken English into learning activities will depend on the course objectives for each lesson, but awarenessraising sessions prior to and during internship training will certainly realize positive and effective outcomes for interns. ELF plays an important role in the students' lives, both inside and outside the classroom (Thon \& Nicoletti, 2018). It may also be advisable to conduct a study by asking foreign guests at the hotel training centre to evaluate their satisfaction of services and attitudes towards interns' communication and performances in order to gain feedback for internship and professional development (Jhaiyanuntana \& Nomnian, 2020). As such, ELF pedagogy can promote an effective teaching paradigm to enhance Thai tourism students' comprehension, acceptance, familiarity, and perceived pleasantness of non-native English accents, as well as encourage favourable attitudes towards them (Inkaew, 2018; Suwannasri, 2016; Suwannasri \& Nomnian, 2017).

\section{CONCLUSION}

The aim of this study was to explore the awareness and attitudes of twenty-eight Thai hotel undergraduate interns towards the varieties of English spoken during their internship as English has gradually become a lingua franca in the hospitality industry at home and overseas. Drawing upon the verbal-guise test of eleven recorded accents for a rating in four dimensions, namely understandability, acceptability, pleasantness, and familiarity, the participants exhibited more favourable attitudes towards familiar accents, pleasant accents and easy-to-understand accents. Moreover, the participants tended to perceive easyto-understand accents as more easily accepted for international communication.

The verbal-guise test showed that the American accent was rated as the preferred accent in all dimensions followed by the Hong Kong and Laotian accents. Only the Korean accent was rated at a low level, which means that the participants had negative attitudes towards the Korean accent. The questionnaire and semi-structured interview findings reveal that the participants were aware of the importance of English as a communication tool and medium language used in the work context. While most of the participants preferred to speak English with an American accent, they also had positive attitudes towards ELF. Furthermore, they considered English to be not just a language for the language owner, but for any users of English. They were impartial whether their conversation partner was a native speaker or not, but were primarily concerned whether they could be understood easily. Although they remained uncertain about the impact of nonnative accents, they recognized that English was the international lingua franca for now and into the future.

This study suggests that teachers of English should not only focus on acquiring the competency of a native speaker but also having their students attain an intelligibility level. Furthermore, it is suggested that positive attitudes towards varieties of English should be encouraged in Thai learners, and English teachers and hotel trainers should regularly expose their students to varieties of English in class. This would allow English learners and hotel student interns to experience actual " unfiltered" communication in their English studies that would better prepare them for the real world of tourism and business, one in which all varieties of English accent is the norm, and communicative effectiveness is more important than native-like competence. Likewise, it is also important to gain feedback from foreign guests and visitors whose views on the interns' performances and use of English can potentially develop the academic program, in-house internship, and hotel services. Consequently, the reciprocal understanding between the interns and guests in terms of communication can be realized and employed for further improvements academically and professionally.

Due to the nature of the case study employed in this study, the findings may not be generalizable to other cases. This study can, however, be considered as a stepping stone for further research with regard to the hotel undergraduate students' internships as an experiential learning process to enhance better international communication for future skilled hotel professionals to strengthen the multilingual tourism and hospitality industry in Thailand. This study hopes to shed light on the appropriate preparation of students in the hotel and tourism industry to increase their professional capability and English language skills that can elevate Thai tourism to meet international standards.

\section{ACKNOWLEDGEMENTS}

The authors would like to thank Dr. Nate-tra Dhevabanchachai, the general manager at the inhouse hotel training centre, for allowing us to conduct this study.

\section{REFERENCES}

Almegren, A. (2018). Saudi students'attitude towards World Englishes. International Journal of Applied Linguistics and English Literature, 7(4), 238-247.

ASEAN secretariat. (2008). The ASEAN Charter. ASEAN Secretariat: Jakarta. 
ASEAN secretariat. (2009). Roadmap for an ASEAN community 2009-2015. ASEAN Secretariat: Jakarta.

Bowden, C., \& Galindo-Gonzalez, S. (2015). Interviewing when you're not face-to-face: The use of email interviews in a phenomenological study. International Journal of Doctoral Studies, 10(12), 79-92.

Bowker, N., \& Tuffin, K. (2004). Using the online medium for discursive research about people with disabilities. Social Science Computer Review, 22(2), 228-241.

Cooper, R. (2009). Online interviewing: It's not as simple as point and click. The Qualitative Report, 14(4), 250-253.

Crocco, O. S., \& Bunwirat, N. (2014). English in ASEAN: Key effects. International Journal of the Computer, the Internet and Management, 22(2), 22-27.

Crystal, D. (2012). A global language In P. Seargeant, \& J. Swann (Eds.). English in the World: History, Diversity, Change (pp.151177). New York: Routledge.

Dhevabanchachai, N., \& Wattanacharoensil, W. (2017). Students' expectations, experiences, and career direction after in-house internship: The pedagogical role of the hotel training center in Thailand. Journal of Teaching in Travel \& Tourism, 17(2), 118-134.

Dolezal, C. (2011). Community-based tourism in Thailand: (dis-)illusions of authenticity and the necessity for dynamic concepts of culture and power. Austrian Journal of South-East Asian Studies, 4(1), 129-138.

Fang, F. (2015). An investigation ofattitudes towards English accents at a Chinese university (Unpublished doctoral dissertation). Faculty of Humanities, University of Southampton, United Kingdom.

Galloway, N., \& Rose, H. (2015). Introducing Global Englishes. New York: Routledge.

Garrett, P. (2010). Attitudes to Language. Cambridge: Cambridge University Press.

Garrett, P., Nikolas, C., \& Angie, W. (2003). Investigating language attitudes: Social meanings of dialect, ethnicity and performance. Cardiff: University of Wales Press.

Inkaew, M. (2018). An exploration of English as a lingua franca communication: A case study of how English is used as a lingua franca among non-native speakers for mutual understanding in an international golf tournament operation in Thailand. rEFLections, 25(2), 42-58.

Inphoo, P., \& Nomnian, S. (2019). Dramatizing a northeastern Thai folklore to lessen high schoolstudents' communication anxiety. PASAA, 57(1), 33-66.
Jenkins, J. (2006). Points of view and blind spots: ELF and SLA. International Journal of Applied Linguistics, 16(2), 137-162.

Jenkins, J. (2007). English as a lingua franca: Attitude and identity. Oxford: Oxford University Press.

Jhaiyanuntana, A., \& Nomnian, S. (2020). Intercultural communication challenges and strategies for the Thai undergraduate hotel interns. PASAA, 59(1), 204-235.

Jindapitak, N. (2010). An attitudinal study of varieties of English: Voices from Thai university English learners. (Unpublished master's thesis). Prince of Songkla University, Songkla, Thailand.

Kachru, B. B. (1985). Standards, codification and sociolinguistic realism: the English language in the outer circle. In R. Quirk, \& H.G. Widdowson,(Eds.), English in the world: Teaching and learning the language and literatures (pp.11-30). Cambridge: Cambridge University Press.

Kirkpatrick, A. (2010). English as an Asian lingua franca and the multilingual model of ELT. Language Teaching, 44(2), 212-224.

Matsuda, A. (2003). The ownership of English in Japanese secondary schools. World Englishes, 22(4), 483-496.

National Statistical Office of Thailand. (2017). The number of the top 10 nationalities to vis it Thailand during 2017. Retrieved from July 22, 2018, from https://www.nso.go.th/more_news.php?cid=46 $5 \&$ filename $=$ inde $x$.

National Statistical Office of Thailand. (2018). The Number of the Top 10 Nationalities to Visit Thailand during 2018. Retrieved from July 22, 2018, from https://www.nso.go.th/more_news.php?cid=50 $2 \&$ filename $=$ inde $x$.

Nomnian, S. (2014a). English as the ASEAN lingua franca in Thai higher education. Veridian $E$ Journal, 7(4), 75-84.

Nomnian, S. (2014b). Thai entrepreneurs' needs of English language for raft service business. Silpakorn University Journal of Social Sciences, Humanities, and Arts, 14(3), 101128.

Nomnian, S. (2014c). Thai entrepreneurs' needs for English language learning materials for the raft service business in Kanchanaburi province. Humanities Journal, 21 (2), 243-275.

Nomnian, S. (2018). Thai doctoral students' layers of identity options through socialacculturation in Australia. Austrian Journal of South-East Asian Studies, 11(1), 99-116.

Nomnian, S., \& Arphattananon, T. (2018). A qualitative study on factors influencing achievement of English language teaching and 
learning in Thai government secondary schools. Asian EFL Journal, 20(6), 207-233.

Office of the National Economic and Social. Development Board. (2017). The National Economic and Social Development Plan (2017-2021). Retrieved from July 22, 2018, from https://www.nesdb.go.th>nesdb_en>ewt_dl_lin $\mathrm{k}$.

Opdenakker, R. (2006). Advantages and disadvantages of four interview techniques in qualitative research. Forum Qualitative Sozialforschung /Forum: Qualitative Social Research, 7(4), Art. 11

Perloff, R. (2003). The dynamics of persuasion. (2nd ed.). London: Lawrence Erlbaum.

Phothongsunan, S. (2017). Perceiving native English speaking teachers: FL university students' perspectives. Arab World English Journal, 8(4), 259-267.

Phumpho, R., \& Nomnian, S. (2019). Challenges of Thai busines seople using English in ASEAN. Kasets art Journal of Social Sciences, 40(4), 743-750.

Prakaianurat, P., \& Kangkun, P. (2018). Language attitudes of Thai working adults toward native and non-native English varieties. Manusya: Journal of Humanities, 21(2), 92-111.

Ruiz-Ballesteros, E. (2017). Keys for approaching community-based tourism. Gazeta de Antropología, 33(1), 1-10.

Rungruangsuparat, B. (2010). Attitudes towards world Englishes of undergraduate students in International Programs of Tourism and Hospitality Management in Thailand (Unpublished doctoral dissertation). International College: Mahidol University).

Seargeant, P. (2012). English in the world today. In P. Seargeant, \& J. Swann (Eds.). English in the world: History, diversity, change.(pp.5-35). New York: Routledge.

Suwannasri, C. (2016). An investigate into awareness and attitudes of vocational students in tourism towards varieties of spoken English as a lingua franca in ASEAN (Unpublished Master's thesis ). Research Institute for Languages and Cultures of Asia: Mahidol University.

Suwannasri, C. \& Nomnian, S. (2017). English as a lingua franca in ASEAN: Researching language attitudes. In M. Meyer, \& Z. Tingshu (Eds.) Multicultural ASEAN: Diversity in identity, language, memory and media (pp.125-150). Nakhon Pathom: MU-MAC.

Taylor-Powell, E., \& Renner, M. (2003). Analyzing qualitative data, program development and evaluation. University of Wisconsin-Extension Cooperative Extension, Madison, Wisconsin. Retrieved from September 20, 2018, from http://learningstore. uwex/edu.

Timmis. I. (2002). Native-speaker norms and international English: A classroom view. ELT Journal, 56(3), 240-249.

Thon, S., \& Nicoletti. K. (2018). The use of English in an English as a lingua franca (ELF) context: A study of ASEAN international students at a Thai university. Veridian E-Journal, 11(4), 227-240.

Zahedpisheh, N., Abu Bakar, Z.B., \& Saffari, N. (2017). English for Tourism and Hospitality Purposes (ETP). English Language Teaching, 10(9), 86-94.

Zourgui, M. (2012). English as a lingua franca in hotel management receptionists' curriculum: A case study of BOU-SAADA Centre (Unpublished doctoral dissertation). University of Chlef, Algeria. 